\title{
Bog ecosystems as a playground for plant- microbe coevolution: bryophytes and vascular plants harbour functionally adapted bacteria
}

\author{
Wisnu Adi Wicaksono ${ }^{1}$, Tomislav Cernava ${ }^{1 *}$ (D) Christian Berg ${ }^{2}$ and Gabriele Berg ${ }^{1,3,4^{*}}$
}

\begin{abstract}
Background: Bogs are unique ecosystems inhabited by distinctive, coevolved assemblages of organisms, which play a global role for carbon storage, climate stability, water quality and biodiversity. To understand ecology and plant-microbe co-occurrence in bogs, we selected 12 representative species of bryophytes and vascular plants and subjected them to a shotgun metagenomic sequencing approach. We explored specific plant-microbe associations as well as functional implications of the respective communities on their host plants and the bog ecosystem.

Results: Microbial communities were shown to be functionally adapted to their plant hosts; a higher colonization specificity was found for vascular plants. Bryophytes that commonly constitute the predominant Sphagnum layer in bogs were characterized by a higher bacterial richness and diversity. Each plant group showed an enrichment of distinct phylogenetic and functional bacterial lineages. Detailed analyses of the metabolic potential of 28 metagenomeassembled genomes (MAGs) supported the observed functional specification of prevalent bacteria. We found that novel lineages of Betaproteobacteria and Actinobacteria in the bog environment harboured genes required for carbon fixation via RuBisCo. Interestingly, several of the highly abundant bacteria in both plant types harboured pathogenicity potential and carried similar virulence factors as found with corresponding human pathogens.

Conclusions: The unexpectedly high specificity of the plant microbiota reflects intimate plant-microbe interactions and coevolution in bog environments. We assume that the detected pathogenicity factors might be involved in coevolution processes, but the finding also reinforces the role of the natural plant microbiota as a potential reservoir for human pathogens. Overall, the study demonstrates how plant-microbe assemblages can ensure stability, functioning and ecosystem health in bogs. It also highlights the role of bog ecosystems as a playground for plant-microbe coevolution.
\end{abstract}

Keywords: Bog ecosystems, Bryophytes, Vascular plants, Microbiome, Coevolution

\section{Introduction}

Bog ecosystems are one of the oldest vegetation forms in the world; they play a central role in the global carbon cycle and storage as well as a source for fresh water [1-3]. This widespread ecosystem is commonly dominated by

*Correspondence: tomislav.cernava@tugraz.at; gabriele.berg@tugraz.at ${ }^{1}$ Institute of Environmental Biotechnology, Graz University of Technology, Graz, Austria

Full list of author information is available at the end of the article
Sphagnum mosses due to their unique biochemical and morphological adaptation to acidic, water-saturated and nutrient-poor environments [4]. As a keystone species group, Sphagnum mosses engineer this ecosystem, i.e. by acidification due to cation exchange and by forming a deep anaerobic peat layer. Well-adapted, non-vascular (acidophytic liverworts and mosses) and vascular plants (graminoids and dwarf shrubs) commonly co-occur in low abundances embedded in the Sphagnum layer [5-7]; therefore, they have different strategies regarding original author(s) and the source, provide a link to the Creative Commons licence, and indicate if changes were made. The images or other third party material in this article are included in the article's Creative Commons licence, unless indicated otherwise in a credit line to the material. If material is not included in the article's Creative Commons licence and your intended use is not permitted by statutory regulation or exceeds the permitted use, you will need to obtain permission directly from the copyright holder. To view a copy of this licence, visit http://creativecommons.org/licenses/by/4.0/. The Creative Commons Public Domain Dedication waiver (http://creativeco mmons.org/publicdomain/zero/1.0/) applies to the data made available in this article, unless otherwise stated in a credit line to the data. 
their growth form and root architecture [6]. Interactions between Sphagnum mosses and the other plants are important for the formation of the hummock topology and nutrient cycling, which facilitates their growth in the bog ecosystem $[5,7]$. The bog microbiome plays a crucial role for bog ecosystem functioning, nutrient cycling and protection towards biotic and abiotic stress [8-10]. Previously, a core microbiome or meta-community of bog plants was identified [11], but knowledge about plant-specific distribution patterns and functions is still missing.

Bacteria are known to be the main constituent of the bog microbiome, co-occurring and interacting with archaea, fungi and other members of the microbiome $[8,12,13]$. Moreover, bog ecosystems were found to be natural hotspots for a high diversity of bacterial species and antagonists [12] and microbial genes [11] and interestingly also for antibiotic resistance genes [4, 11, 14]. A vast majority of bog bacteria were found to engage in a plant-associated, often endophytic life style [4]. The plant microbiota is involved in plant growth, productivity, adaptation, diversification and health [15-17], which is of special importance under extreme conditions in bog environments. Specifically, Sphagnum mosses were shown to contain a specific bacterial community which fulfils important roles for ecosystem functioning and health $[1,8,12,18-21]$. A previous study indicated that Acidobacteria, Actinobacteria and Proteobacteria are highly responsive towards substrate-specific changes in the bog ecosystem [22]. Interestingly, studies indicate an extraordinary high degree of plant-specific microorganisms $[11,18,23]$; this can be explained by plantmicrobe coevolution [17]. Coevolution was especially studied for microbial symbionts and pathogens, but the degree to which specialization and coevolution between plant species and microbes in ecosystems occur is relatively understudied [24]. For bogs, our hypothesis is that vascular plants with vascular tissues, which allow transport and diversification and which have more developed defence mechanisms against pathogens [25], harbour a more specific but less diverse microbiota than the phylogenetically older bryophytes.

Therefore, we studied bacterial community structures and functions in typical circumpolar bog vegetation of two Austrian bogs (Rotmoos and Pürgschachen Moor). We selected representative plants that belong to two separate phylogenetic branches, bryophytes, i.e. Sphagnum magellanicum, Sphagnum angustifolium and Sphagnum fuscum (peat mosses), Pleurozium schreberi (Brid.) Mitt. (Schreber's big red stem moss), Polytrichum strictum (bog haircap moss) and Mylia anomala (anomalous flapwort; liverwort), and vascular plants, i.e. Vaccinium myrtillus (European blueberry), Vaccinium oxycoccus (bog cranberry), Calluna vulgaris (heather), Andromeda polifolia (bog rosemary), Eriophorum vaginatum (tussock cottongrass) and Pinus mugo (dwarf mountain pine), and analysed them using a shotgun metagenomic sequencing approach. In combination with targeted bioinformatics, such data can be used for functional microbiota profiling and to capture detailed taxonomic diversity of the entire microbiome [26]. Specifically, we addressed the following questions: (i) Are there general differences in bacterial communities between bryophytes and vascular plants? (ii) Do bacteria harbour functions that are specific for the different plant host interactions? and (iii) Do different bacterial taxa have distinct roles to support bog ecosystem functioning? Overall, this study provides key insights into the ecosystem function of bog-associated bacteria that are at present largely underrepresented in global surveys.

\section{Material and methods}

\section{Sample collection and shotgun metagenomic sequencing}

The samples for the analyses were obtained from northern Styria, Austria, in November 2012 within two geographically distinct peat bogs, Rotmoos (N47 41.029 E15 09.284 and N47 41.059 E1509.269) and Pürgschachen Moor (N47 34.835 E14 20.390 and N47 34.815 E14 20.482). In the past, the microbiome in these two bogs was intensively studied with a comprehensive experimental design [23, 27]. Based on these results, which showed markedly high species specificity of microbial communities, we developed a specific design for metagenomics approaches, which were already used to describe ecosystem functioning under extreme conditions as well as the role of archaea $[11,28]$. At both sites, we selected randomly two plots (each of $1 \mathrm{~m}^{2}$ ) that represent the two typical plant communities dominated by either Sphagnum magellanicum or Sphagnum angustifolium. Bryophytes and vascular plants included in this study represent exemplary species that grow naturally in peat bogs; plant cover per plot together with environmental variables are detailed in Table S1. The metagenomic datasets (Table S2) were generated as previously described $[11,28]$. In brief, total genomic DNA was extracted using the FastDNA Spin kit for soil (MP Biomedical, USA) following the manufacturer's protocol. Shotgun metagenomic sequencing was performed by the sequencing provider Eurofins MWG Operon (Ebersberg, Germany). DNA library preparation was performed using a TruSeq DNA library kit (Illumina, USA) before the sequencing. The extracted DNA was then sequenced using an Illumina HiSeq 2500 system PE $2 \times 150$ bp (Illumina, USA) resulting in a range of $22.7-40.9$ million reads per individual metagenome (Table S2). The datasets were previously used to explore archaeal community structure and 
function [28]. However, they remained entirely unexplored in terms of bacterial diversity which was previously one of the main constituents of bog microbiome $[8,27]$. In the present study, the available raw data was subjected to a targeted bioinformatic approach to address this important component of the microbiome.

\section{Bacterial community structure and diversity analysis}

Kraken2 v2.0.9 and Bracken v2.6.0 were used to measure the bacterial taxonomic composition and estimate the diversity of the short-read sequencing samples [29, 30]. Kraken2 implements a $k$-mer-based approach to classify individual metagenome reads by mapping all $k$-mer to the lowest common ancestor (LCA) of all genomes containing the given $k$-mer. The standard Kraken2 database was used to classify individual reads. Following Kraken2 taxonomic assignment, Bracken was used to estimate species abundances. To account for uneven sequencing depth, the datasets were normalized by rarefying to the lowest number of reads $(2,271,071)$ and using MetagenomeSeq's cumulative sum scaling (CSS; [31]) for subsequent alpha (species richness) and beta (variation in species composition) diversity analysis, respectively. Phyloseq, MicrobiomeAnalyst and vegan $\mathrm{R}$ packages implemented in RStudio v 1.3.1093 were used to analyse bacterial community diversity and composition [32-37]. Significant differences in alpha diversity estimates using the number of species $(S)$ and Shannon index $\left(H^{\prime}\right)$ were determined by a non-parametric (ranked-based) Kruskal-Wallis test. The normalized Bray-Curtis dissimilarity matrix was subjected to analysis of similarities (ANOSIM) to test for significant effects of factors on microbial community structures. Biomarkers at bacterial order level between vascular plants and bryophytes were identified using a linear discriminant analysis effect size (LefSe) [38]. The threshold of Linear Discriminant Analysis (LDA) was set as 1 with cut-off $P_{\text {adjusted }}$ values of 0.1 .

\section{Non-redundant gene profiles of bog microbial communities}

Default parameters were used for all mentioned software unless otherwise noted. The overall sequencing quality was assessed using FastQC v0.11.5 [39]. Based on the results, quality filtering was subsequently performed using Trimmomatic v0.39 and VSEARCH v2.14.2 to remove Illumina adaptor and low-quality reads (Phred $<20)$, respectively. The metagenome datasets were co-assembled using MEGAHIT v1.2.9 with meta-sensitive parameters [40]. Only contigs with a length $>1 \mathrm{~kb}$ were kept for subsequent analyses. Prodigal v2.6.3 was used to predict open reading frames of the assembled metagenome contigs [41]. Predicted protein-coding gene sequences were clustered into a non-redundant gene catalogue using CD-HIT-EST v4.8.1 at 95\% nucleotide identity [42]. Representative gene sequences were then annotated using the blast algorithm in DIAMOND v0.9.35.136 through eggNOG-mapper v1.0.3 [43, 44] against the eggNOG database v5.0 [45] to reveal an ecologically relevant functional subsystem. Only reads mapped to contigs with KEGG Orthology (KO) annotation information were retained to calculate the abundances of genes and functional categories. To estimate gene abundance, the quality-filtered reads were mapped back to the abovementioned non-redundant gene catalogue using BWA v 0.7.17 and SamTools v1.7 [46, 47]. All non-bacterial contigs were removed before further analysis. In addition, low abundant genes (less than 100 reads) were removed to improve the sensitivity of differential gene abundance analyses. Differential gene abundance analysis was performed using edgeR as a suitable statistical method for the identification of differentially abundant genes in metagenomes $[48,49]$. KO with $\log _{2}$ fold change $>1$ and $P_{\text {adjusted }}$ values below 0.1 were defined to be enriched or reduced between bryophytes and vascular plants. Beta diversity analysis (variation in $\mathrm{KO}$ composition) was performed as described for the taxonomic analyses. KO-pathway mapping was performed using the KEGG mapper [50].

\section{Detection of nitrogen cycling genes in metagenomic data}

Reads from the metagenomes were aligned against $\mathrm{NCy}$ $\mathrm{cDB}$, a manually curated integrative database for nitrogen cycle gene profiling from shotgun metagenome sequencing data [51] using the blast algorithm in DIAMOND v0.9.35.136 [43]. We used a high confidence approach with a similarity threshold of $90 \%$ in combination with a stringent $E$-value $<10^{-5}$ to assign the metagenomic reads to nitrogen cycle genes [52]. Beta diversity and differential gene abundance analysis were performed as mentioned above.

\section{Reconstruction of bacterial metagenome-assembled genomes}

Multiple binning methods, i.e. Maxbin2 v2.2.7, MetaBAT2 v2.12.1 and CONCOCT v1.1.0 [53-55], were used to reconstruct metagenome-assembled genomes (MAGs) as previously described [56]. The MAGs were then dereplicated using DASTool v1.1.1 [57]. CheckM v1.0.13 was used to calculate genome coverage, completeness and the percentage of contaminations in the MAGs [58]. Only medium-quality MAGs according to the current definition of the minimum information metagenome-assembled genome (MIMAG) standards [59] and with at least $80 \%$ completeness were kept for downstream analysis. Taxonomical classification of each MAG was identified using the Bin Annotation Tool (BAT) v4.6 [60]. Prediction 
of protein-coding genes and gene annotations were performed as described for the general metagenomic analyses. We further searched for virulence factors in the MAGs by implementing the Virulence Factors of Pathogenic Bacteria Database (VFDB; [61]). For the detection of potential virulence genes, a similarity threshold of $50 \%$ in combination with a stringent $E$-value $<10^{-10}$ was used to avoid false-positive hits [62]. We included clinical isolate genomes that are publicly available (Table S3) to compare virulence gene composition between the MAGs and them. Detailed phylogenetic analysis of the MAGs was performed using PhyloPhlAn v3.0 [63]. Abundance profiles of each MAGs were estimated by back mapping back the quality-filtered reads from each plant shotgun metagenomic dataset to MAG contigs using the same approach as described above. MAG abundance was quantified as mapped reads per kilobase per million reads (RPKM) divided by the metagenomic sample sizes (in millions of reads) and the length of the MAG in kilobases. Differences in MAG abundances between bryophytes and vascular plants were analysed using the pairwise Wilcox test. Counts of KO from each MAGs were used as input data to calculate distance matrix using Bray-Curtis dissimilarities. For analysing virulence gene compositions, a Jaccard dissimilarity matrix based on the presence/absence of these genes was used to generate hierarchical clustering [36]. The generated distance matrix was subjected for PERMANOVA to investigate if MAG phylogeny explains the composition of functional genes within the MAGs. The distance matrix was further visualized by using principal coordinate analysis (PCoA) plots. A heatmap plot was used to visualize the functional feature abundance profiles. Venn diagram was generated using InteractiVenn [64].

\section{Results}

\section{Bacterial diversity with the bog vegetation}

Targeted diversity analyses were conducted in order to resolve if bacterial community richness and structure differ between vascular plants and bryophytes although they grew in close proximity and all individuals were embedded into Sphagnum mosses. Alpha diversity analysis indicated that plant types (vascular plants and bryophytes) significantly affected bacterial richness and community structure (Fig. 1a). Based on the Kraken2 taxonomic classifier, a total of 5699 bacterial species was identified within the metagenome sequence library. Respective rarefaction curves indicate the sampling size was sufficient to capture overall bacterial diversity (Figure S1). A significantly higher number of species $(P=0.025)$ and Shannon index $(P=0.016)$ was observed in bryophytes $\left(S=5533, H^{\prime}=7.0\right)$ in comparison to vascular plants $\left(S=5451, H^{\prime}=6.7\right.$; Fig. 1a). A total of 37 core taxa with a relative abundance $>0.01 \%$ were exclusively detected in bryophytes. Beta diversity analysis revealed significantly different clustering between bacterial community structures of vascular plants and bryophytes $\left(R^{2}=0.229, P=0.004\right.$; Fig. 1b). Additional beta diversity analyses were performed by analysing bacterial communities on phylum, order and genus levels (Figure S2). At higher taxonomic levels (phylum and class), the bacterial community composition was relatively similar between bryophytes and vascular plants $\left(R^{2}=0.175, P=0.140\right.$; $R^{2}=0.130, P=0.124$; Figure $\left.\mathrm{S} 2 \mathrm{a} \& \mathrm{~b}\right)$. However, a distinct clustering between the two groups was observed at lower taxonomic levels (order and genus) when subjected to the same analysis $\left(R^{2}=0.250, P=0.015 ; R^{2}=0.218, P=0.004\right.$; Figure S2c \& d).

Among bacterial phyla, Proteobacteria (74.1\%) was the predominant taxonomic group in the bog vegetation followed by Actinobacteria (14.7\%) and Acidobacteria (4.2\%). Specific differences in bacterial composition were observed at lower taxonomic levels. A relatively higher proportion of Alphaproteobacteria and Gammaproteobacteria was observed for vascular plants (38.2 and $20.4 \%$, respectively; Fig. 1c) in comparison to bryophytes (36.5 and 16.4\%). In contrast, the bacterial class Acidobacteria was relatively more abundant in bryophytes (4.9\%) compared to vascular plants (3.4\%). A complementary LEfSe analysis indicated that several bacterial lineages within Proteobacteria (i.e. Rhizobiales, Pseudomonadales, Xanthomonadales and Pasteurellales) and Cyanobacteria (i.e. Synechococcales, Nostocales, Synechococcales, Chroococcales) were significantly enriched in vascular plants whereas bacterial lineages that belong to Verrucomicrobia (i.e. Verrucomicrobiales and Opitutales) and Planctomycetes (i.e. Planctomycetales) were significantly enriched in bryophytes (Fig. 1d).

\section{Profiling of bacterial functions in the bog microbiome}

Due to the observed differences in the bacterial community structure, we expected that the overall functional profiles of the respective communities would be also different. Following filtering of metagenomic data, $8.56 \times 10^{6}-27.9 \times 10^{6}$ reads were annotated as bacterial genes (Table S2). Functional annotation assigned the reads into $5852 \mathrm{KOs}$. A high proportion of them $(5522$ KOs; 94.3\%) was detected in all samples indicating a large functional core in the bog microbiome. The KOs were mainly associated with carbohydrate, amino acid and energy metabolism (22.1, 18.8 and $12.3 \%$, respectively; Fig. 2a). Moreover, specific KOs were associated with functions known to be prevalent in plant-associated microbes, i.e. $\mathrm{ABC}$ transporters $(n=220,3.8 \%)$, quorum sensing $(n=63,1.1 \%)$, nitrogen metabolism $(n=41$, $0.7 \%)$ and biosynthesis of siderophores $(n=20,0.34 \%)$. 

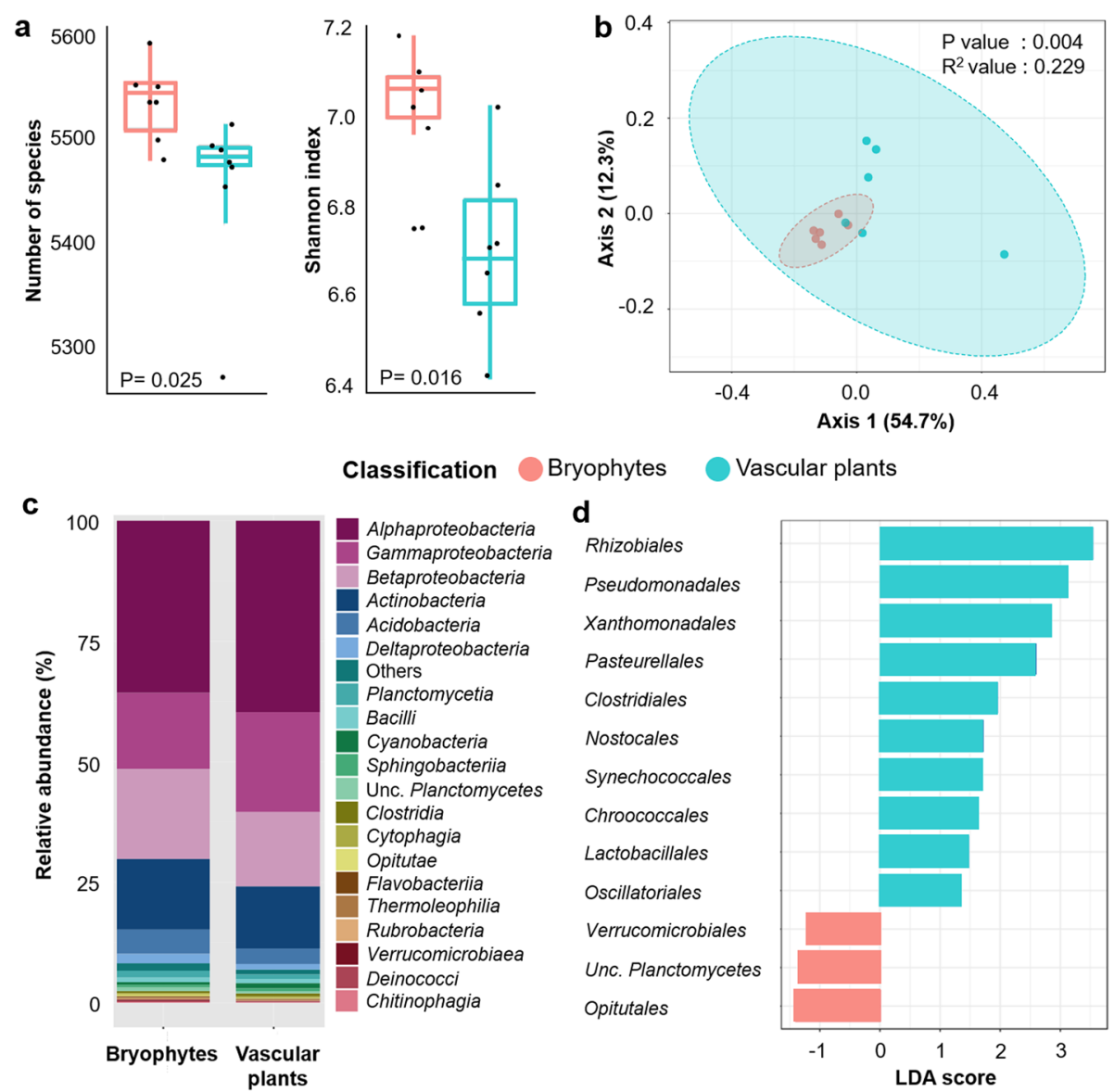

d

Rhizobiales

Pseudomonadales Xanthomonadales Pasteurellales Clostridiales Nostocales Synechococcales Chroococcales

Lactobacillales

Oscillatoriales Verrucomicrobiales Unc. Planctomycetes Opitutales

Vascular plants

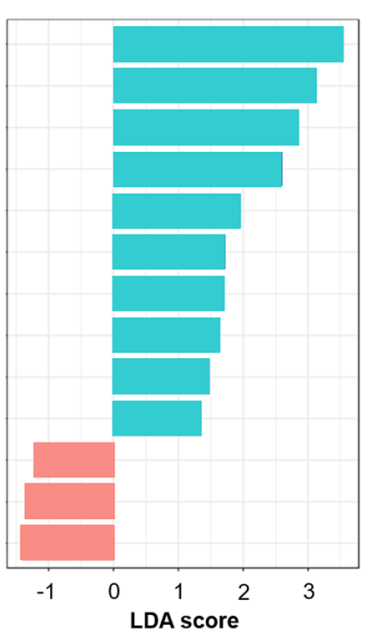

Fig. 1 Bacterial richness, community clustering, composition and identified taxa that are either specific for bryophytes or vascular plants. Bacterial richness was assessed with the Shannon index (a). Community clustering of bacteria in bryophytes and vascular plants is visualized in a two-dimensional PCoA plot based on a Bray-Curtis matrix (b). Bacterial composition is shown at the class level (c). LEfSe analysis indicated specific biomarkers at bacterial order for both plant groups. Only bacterial taxa with LDA scores $>1$ and $P_{\text {adjusted }}<0.1$ according to LEfSe analysis are shown (d)

Methane oxidizing bacteria are important to reduce methane emissions from peat bogs and provide $\mathrm{CO}_{2}$ for photosynthesis [1]. We also detected genes involved in methane oxidation, i.e. pmoA, pmoB, pmoC and $m m o X$ that belong to Alphaproteobacteria. Altogether, beta diversity analysis indicated a clear clustering for microbiota's functioning in bryophytes and vascular plants $\left(R^{2}=22.9 \%, P=0.004\right.$; Fig. $\left.2 \mathrm{~b}\right)$.

A pairwise comparison using edgeR revealed that 290 KOs $\left(\log _{2}\right.$ fold change $>1, P_{\text {adjusted }}<0.1$, Table S4) were significantly different between bryophytes and vascular plants. A total of $216 \mathrm{KOs}$ was significantly enriched in vascular plants, whereas $74 \mathrm{KOs}$ were reduced (Fig. 2c). Among the enriched $\mathrm{KOs}, 33$ were assigned to $\mathrm{ABC}$ transporter pathways in vascular plants. Moreover, four KOs that were involved in oligosaccharide (i.e. galactose, raffinose and sorbitol), six KOs that were involved in monosaccharide (i.e. L-arabinose and xylitol) and six
KOs that were involved in biotin and amino acid transporters (i.e. octopine and cystine) were enriched in vascular plants whereas two KOs assigned to bicarbonate transport system substrate-binding protein and cobalt/ nickel transport system permease protein were enriched in bryophytes. A higher abundance of KOs $(n=6)$ that are related to the biosynthesis of other secondary metabolites (i.e. pinoresinol/lariciresinol reductase and antibiotic kanosamine) was also observed in vascular plants. In addition, a total of three KOs related to the biosynthesis of vitamins, i.e. vitamin $\mathrm{K} 2, \mathrm{~B} 1$ and $\mathrm{B} 12$, were also enriched in vascular plants. The siderophore group represented by aerobacterin (K03897 and K03894), yersiniabactin (K04784) and mycobactin (K04789 and K04792) was also more abundant in vascular plants compared to bryophytes, whereas the siderophore enterobactin $(\mathrm{k} 02361)$ showed the opposite trend. Within nitrogen metabolism, six KOs annotated as nitrogenase and nitrate 

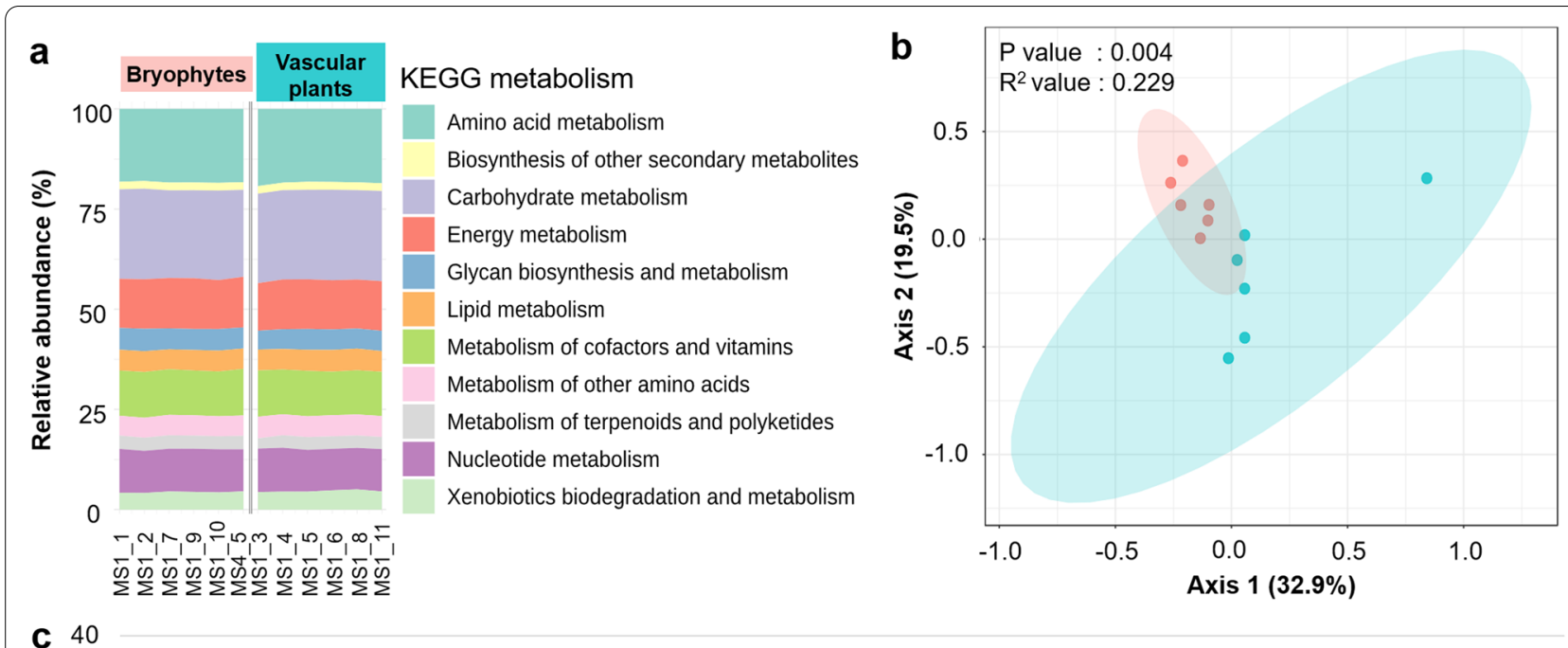

C 40

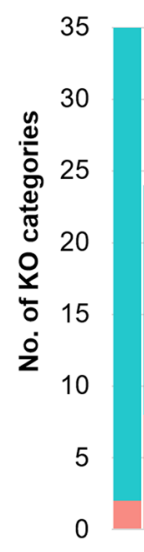

Classification Bryophytes Vascular plants

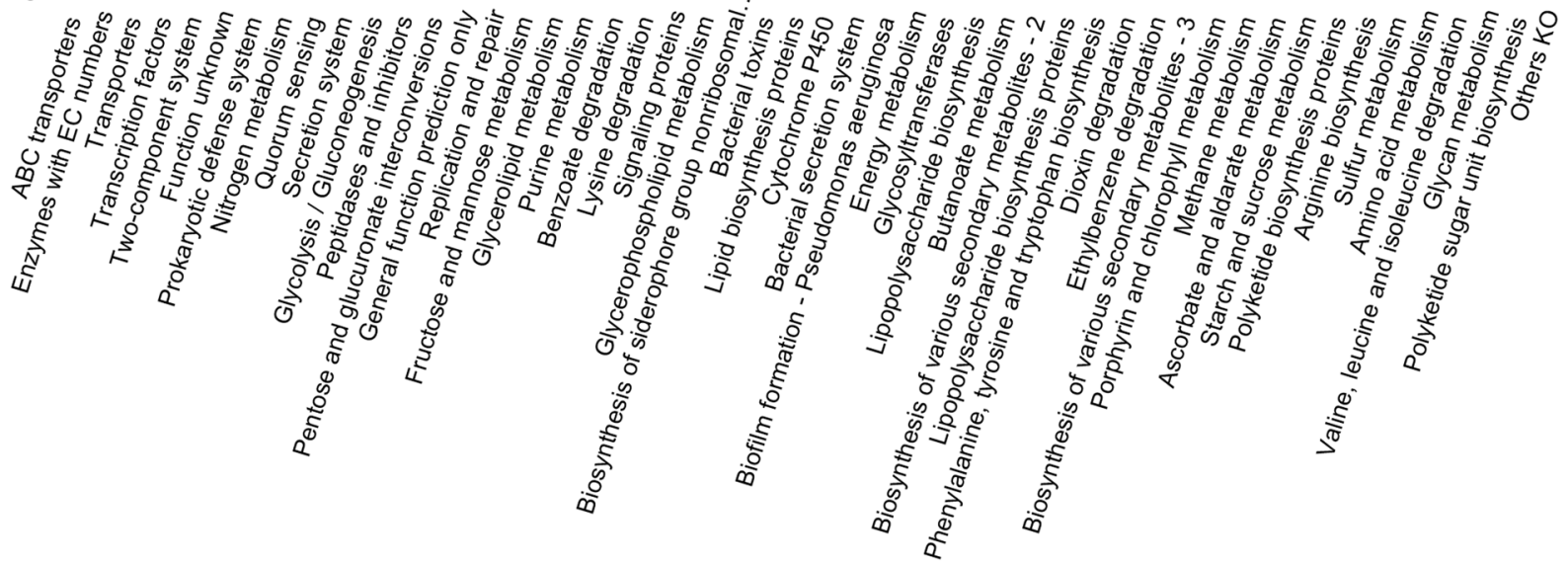

Fig. 2 Comparison of functional assignment of the bog-associated microbiome, functional community clustering (a, b) and number of bacterial KEGG Orthology (KO) that enriched or depleted between bryophytes and vascular plants (c). Annotated genes were assigned to corresponding KEGG Orthology (KO) functional categories (a). A Bray-Curtis distance matrix between samples was visualized using a principal coordinate analysis (PCOA) plot (b). c Numbers of bacterial genes that were statistically enriched/depleted according to differential gene abundance analysis were obtained by using edgeR ( $\log _{2}$ fold change $>1$ and $P_{\text {adjusted }}$ values below 0.1 ). These genes were grouped according to KEGG pathways (third tier) and visualized in a bar plot (c) 
reductase (nifH-K02588, nifK-K02591, narG-K00370, narH-K00371, nifD-KO2586 and napA-K02567) were enriched in vascular plants. Contigs that were assigned to nifH originated from Alphaproteobacteria and Betaproteobacteria. In contrast, KOs involved in degradation of lysine $(n=3)$, dioxin $(n=2)$ and aromatic compounds, i.e. aminobenzoate $(n=3)$, ethylbenzene $(n=2)$, naphthalene $(n=1)$, chlorocyclohexane $(n=1)$ and chlorobenzene $(n=1)$, were enriched in bryophytes. Notably, specific CRISPR-associated proteins $(n=6)$ were also enriched in the bryophytes indicating potentially higher selection pressures from bacteriophages in these plants (Fig. 2c). The overall results indicate that despite a high share of functional features, the plant hosts enrich not only certain taxonomic groups (Fig. 1d), but also distinct functional groups to support host functioning.

\section{Profiling of nitrogen cycling genes in the bog microbiome}

As the nitrogen cycle is an important biogeochemical pathway in the bog ecosystem, we further explored if the respective communities (associated to bryophytes and vascular plants) were associated to distinct nitrogen cycling profiles. Using a high-stringency approach $(90 \%$ similarity and $<10^{-5} E$-value), a total of 234,505 reads (ranging from 6417 to 36,098 reads per plant) was annotated as nitrogen cycling genes (Table S2). Beta diversity analysis indicated a distinct cluster between bryophytes and vascular plants $\left(R^{2}=47.6 \%, P=0.003\right.$; Fig. $\left.3 a\right)$. Furthermore, a pairwise comparison using edgeR indicated that the abundance of genes that are involved in nitrogen fixation and denitrification was significantly higher in bryophytes compared to vascular plants (Fig. 3b, Table S5). However, the differences in log-fold change were only 0.7 and 0.4 , respectively. When abundance profiles were analysed at the gene level, we observed that 11 genes that are involved in nitrogen cycling (Table S5) significantly differed between bryophytes and vascular plants. The abundance of the nifH gene was significantly higher in bryophytes. This result was in contrast to the abundance analysis using the eggNOG database (Table S4, see K02588-nifH) that indicated that the abundance of nifH was higher in vascular plants. A set of genes encoding particulate methane monooxygenase ( $p m o B$ and $p m o C$ ) which also have a shared high sequence similarity with the amo gene family [51] were enriched in vascular plants (Fig. 3). Genes encoding nitrate reductase $(\mathrm{NAD}(\mathrm{P}) \mathrm{H})(N R)$, glutamate synthase [NADH] $(G L T 1)$ and nitrate reductase (narH) were also enriched in the vascular plants.

\section{Genome-centric analysis of prevalent bacteria in the bog vegetation}

In total, 28 MAGs with completeness levels more than $80 \%$ and contamination levels lower than $10 \%$ were reconstructed from bog metagenome datasets representing the most abundant members of the bacterial communities. Taxonomical assignment (Fig. 4a, Table S6) MAGs (completeness $>80 \%$ ) resulted in the classification to six phyla, i.e. Proteobacteria $(n=11)$, Acidobacteria $(n=6)$, Actinobacteria $(n=6)$, Verrucomicrobia
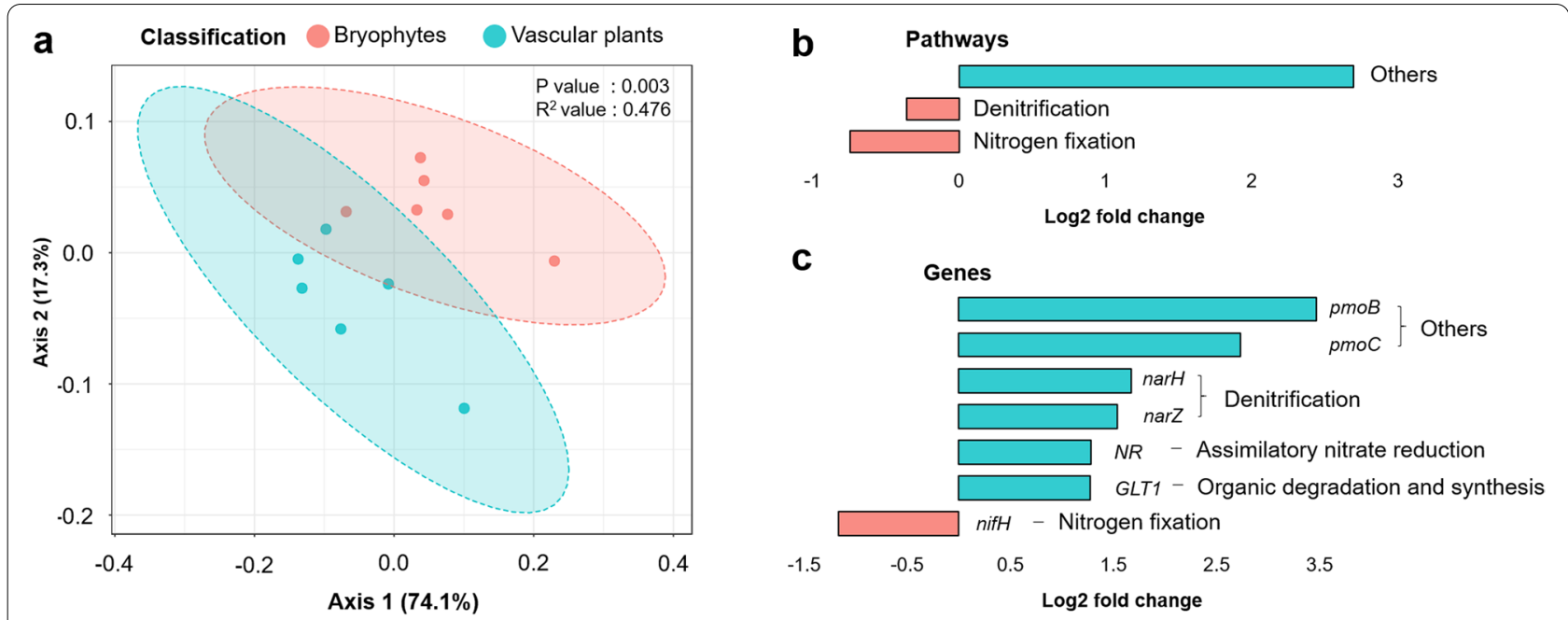

Fig. 3 Clustering of nitrogen cycling gene profiles in vascular plants and bryophytes (a) and bar plots showing pathways (b) and genes (c) involved in nitrogen cycling that were enriched or reduced. A Bray-Curtis distance matrix between samples was visualized using a principal coordinate analysis (PCOA) plot (a). Pathways that were statistically enriched/reduced according to edgeR $\left(P_{\text {adjusted }}<0.1\right)$ were included (b). Nitrogen cycling genes that were statistically enriched/reduced according to edgeR $\left(\log _{2}\right.$ fold change $>1$ and $\left.P_{\text {adjusted }}<0.1\right)$ were included (c). Negative $\log _{2}$ fold change values indicate that the respective genes are more abundant in bryophytes whereas positive values indicate that the genes are more abundant in vascular plants 

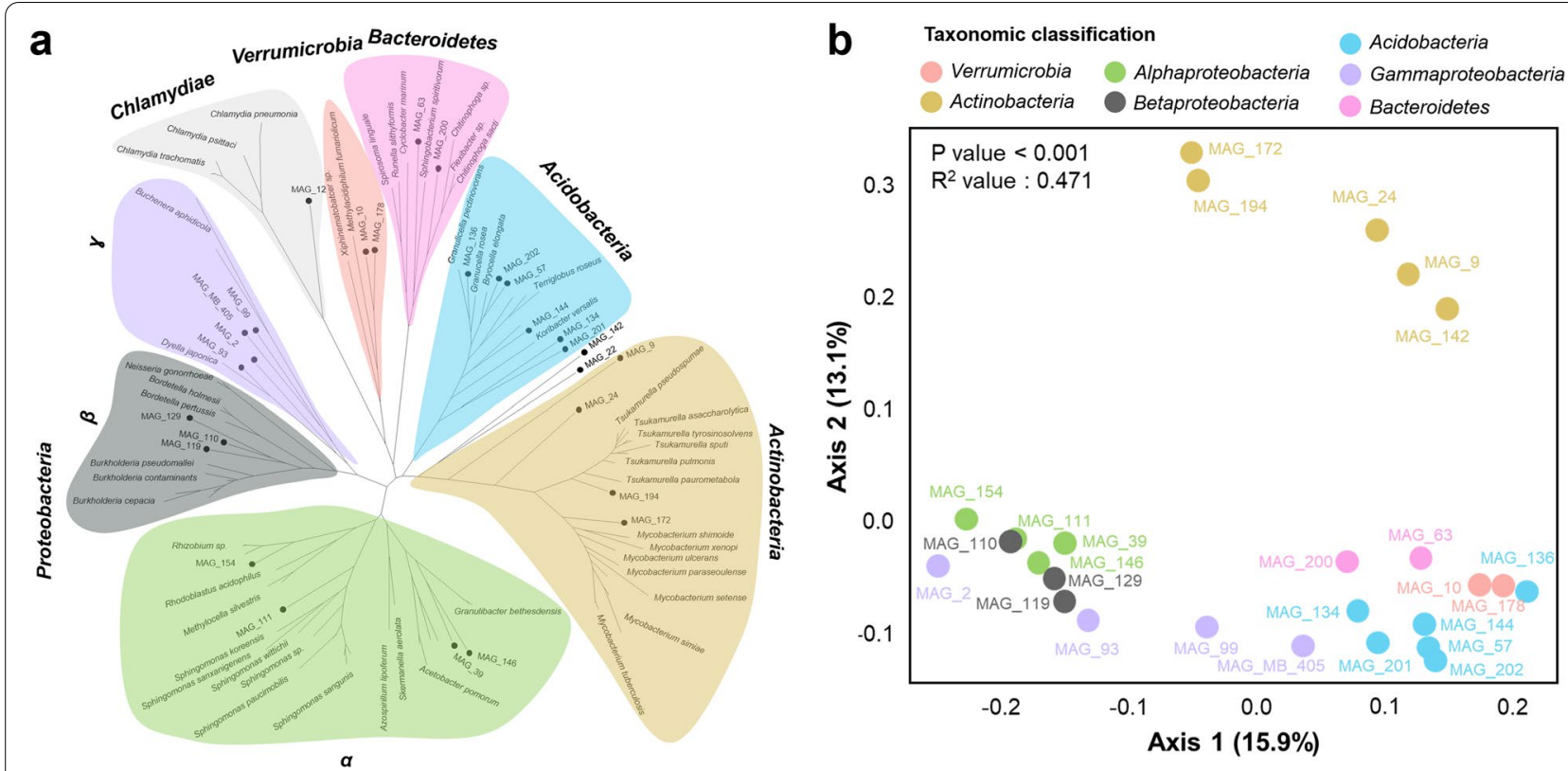

Fig. 4 Phylogenetic tree of reconstructed metagenome-assembled genomes (MAGs) and clustering based on KEGG Orthology (KO) counts from each MAG. Different bacterial phylum and proteobacterial classes that are presented in the phylogenetic tree constructed MAGs are highlighted with different colours (a). Dots represent MAGs that were generated with metagenomic data from the bog ecosystem. Principal coordinate analysis (PCOA) of MAG clusters is based on KO counts in the genomes (b)

$(n=2)$, Bacteroidetes $(n=2)$ and Chlamydiae $(n=1)$. One MAG was assigned to Candidatus Eremiobacteraeota which was previously known as Candidate division WPS-2 (bin ID: MAG_22). Despite high completeness (>90\%), several MAGs were only assignable at the class level, i.e. Gammaproteobacteria (MAG_2, MAG_99) and Betaproteobacteria (MAG_119, MAG_129, MAG_110), indicating a possible occurrence of novel bacterial lineages in the bog microbiome. Among MAGs, two MAGs (MAG_178 and MAG_201) that belong to Verrucomicrobia and Acidobacteria, respectively, were more abundant in non-vascular plants whereas four MAGs that belong to Proteobacteria (MAG_154, MAG_111, MAG_2 and MAG_119) were more abundant in vascular plants $\left(P_{\text {ad- }}\right.$ justed $<0.1$, Table S7). This result indicated that despite similar abundances from the majority of MAGs, the plant host seems to allow specific bacterial taxa to enrich as shown previously (Fig. 1d).

A broad phylogenetic representation of bacteria and high genome completeness facilitated detailed assessments of the functional potential of different taxonomic groups in the bog vegetation. MAGs belonging to Chlamydiae (MAG_12) and Candidatus Eremiobacteraeota (Candidate division WPS-2; MAG_22) were excluded from the PERMANOVA analysis due to insufficient replicates for these groups (Fig. 4, Table S6). Function-based clustering in a PCoA plot indicated the occurrence of specific clusters was determined by MAG phylogeny (Fig. 3b). This was confirmed by a complementary statistical assessment with PERMANOVA $\left(P<0.001, R^{2}=0.471\right)$. Three distinct clusters were observed, i.e. cluster 1 (Actinobacteria MAGs), cluster 2 (Alpha-, Beta- and Gammaproteobacteria) and cluster 3 (Acidobacteria, Bacteroidetes and Verrucomicrobia). This observation indicates that various functional groups are present within naturally occurring bacterial communities in the bog vegetation. In a subsequent step, functions that differed between MAGs (Fig. 5) and that might be involved in plant-microbe interactions were explored in detail. Alpha-, Beta-, Gammaproteobacteria and Actinobacteria encoded a higher number of genes involved in carbon fixation pathways, i.e. ato $B$ (acetyl-CoA C-acetyltransferase) and $s d h D$. In fact, the majority of MAGs that belong to Alpha-, Beta-, Gammaproteobacteria and Actinobacteria had a complete gene set of $s d h A B C D / f d r A B C D$. The latter taxa also had a higher number of genes involved in carbon fixation pathways, i.e. $m c l$ (citramalyl-CoA lyase), than other MAG groups whereas Alpha-, Beta- and Gammaproteobacteria harboured a higher number of $p t a$ gene encode phosphate acetyltransferase. Moreover, we also detected small and large subunits of RuBisCO genes and aceA which encodes isocitrate lyase in three MAGs (MAG_39, MAG_129 and MAG_194) that were assigned to Alpha-, 


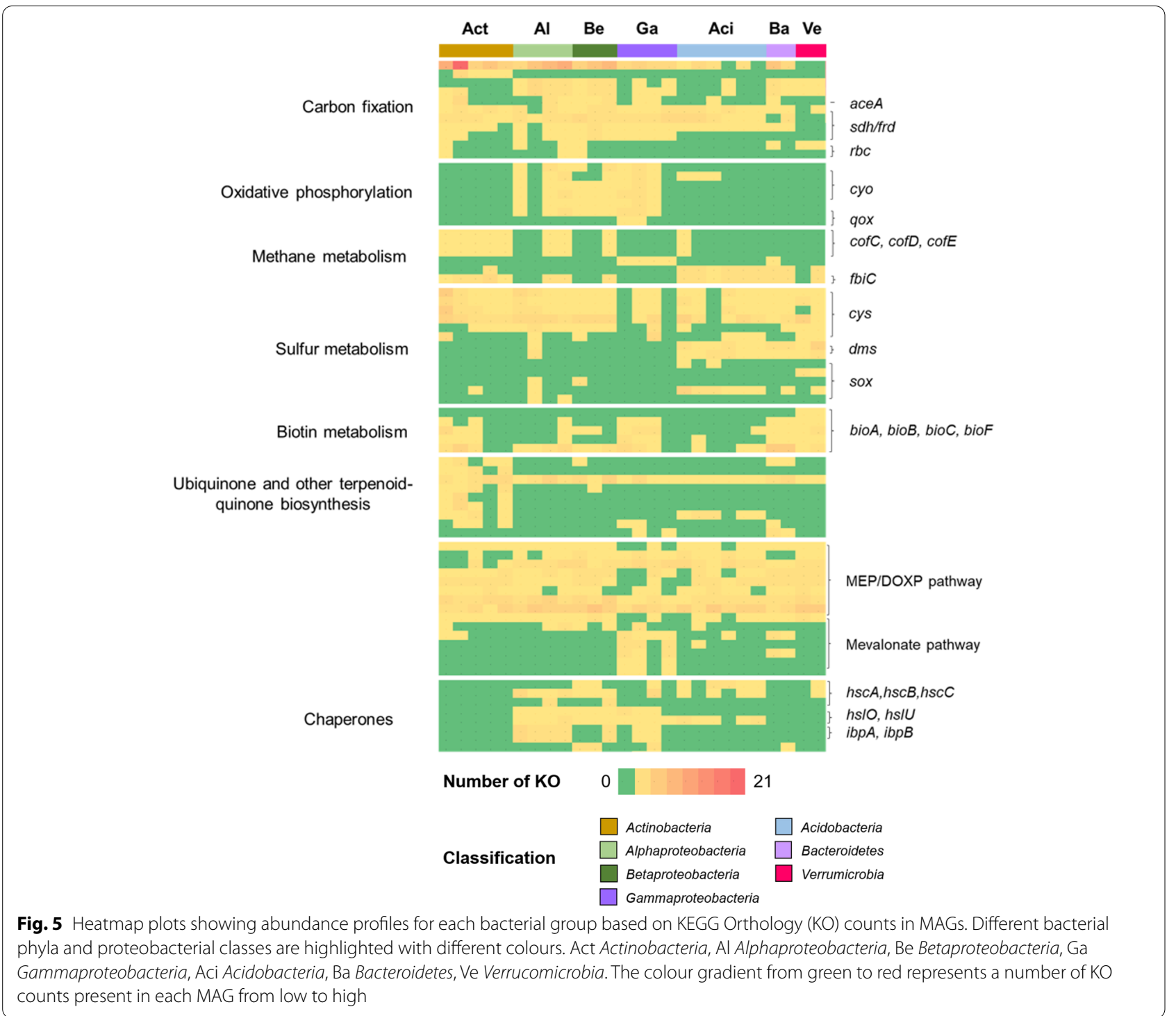

Betaproteobacteria and Actinobacteria. A set of genes that are involved in oxidative phosphorylation, especially cytochrome o ubiquinol oxidase (cyo) and cytochrome aa3 quinol oxidase (qox), were found to be more prevalent in MAGs of the Proteobacteria phylum compared to others (Fig. 5). Proteobacteria and Actinobacteria might play a crucial role in carbon fixation in the bog ecosystem (Fig. 5). The latter taxa also had a set of genes that are involved in $\mathrm{F} 420$ biosynthesis, which plays a central role in methanogenesis due to the presence of $\operatorname{cof} C, \operatorname{cof} D, \operatorname{cof} E$ and $\mathrm{fbiC}$. Genes involved in assimilatory sulfate reduction were evenly distributed (cys $N, c y s D, c y s N C, c y s I$ and $c y s)$ among MAGs. However, Acidobacteria and Verrucomicrobia harboured a higher number of genes related to sulfur metabolism through the Sox system such as $\operatorname{sox} B$ and soxX, respectively (Fig. 5). Genes that are involved in assimilatory/dissimilatory nitrate reduction such as narB, nirA, nirB and nirD were detected in MAGs that belong to Actinobacteria (MAG_194 and MAG_172), Alphaproteobacteria (MAG_111), Betaproteobacteria (MAG_129 and MAG_110) and Gammaproteobacteria (MAG_2).

In addition to genes from the central carbohydrate and energy metabolism, also, genes that are related to vitamin biosynthesis, metabolism of secondary metabolites and abiotic stress responses and thus potentially important for host-microbe interactions were detected. A set of genes (bioA, bioB, bioC and bioF) that is involved in biotin metabolism was detected in MAGs that belong to Actinobacteria, Gammaproteobacteria, Bacteroidetes and Verrucomicrobia. Specific genes involved in 
menaquinone biosynthesis (men $A, \operatorname{men} B, \operatorname{men} C$, mend and $m e n F$ ) were prevalent in Actinobacteria. A collection of genes involved in the MEP/DOXP pathway $(d x r$, isp $A$, $i s p B$, ispD, ispE, ispF, gcpE, ispH and idsA) were detected in the majority of MAGs, except from those that belong to Gammaproteobacteria. Interestingly, Gammaproteobacteria may also play an important role in the production of terpenoid but through the mevalonate pathway due to the presence of $i d i, m v a A, m v a D, m v k$ and $m v k A 2$ genes (Fig. 5). Several molecular chaperones, i.e. hslO, $i b p A, i b p B$ and $p c c A$, were more prevalent in MAGs that belong to Proteobacteria, which indicates their enhanced ability to mitigate environmental stress.

Among the MAGs, two MAGs (MAG_178 and MAG_201) that were assigned to Verrucomicrobia and Acidobacteria, respectively, were more abundant in bryophytes. In contrast, four MAGs that belong to Proteobacteria (MAG_154, MAG_111, MAG_2 and MAG_119) were more abundant in vascular plants $\left(P_{\text {adjusted }}<0.1\right.$; Table S7). A key feature that was found in MAG_178 and MAG_201. was that these MAGs harboured a complete set of enzymes that are involved in riboflavin (B2) biosynthesis, i.e. GTP cyclohydrolase II and riboflavin synthase. On the other hand, all of the MAGs that were more prevalent in vascular plants harboured genes that encode urea transport system permease protein (urtA, urtB, urtC, urtD and urtE). In particular, MAG_154 also harboured genes that encode multiple sugar transport system ATP-binding proteins. These results indicate that despite similar abundances of the majority of analysed MAGs, that plant host likely facilitates colonization of bacterial taxa with specific functions (Fig. 1) to support plant host physiology.

Previous studies provided first indications that the keystone species in the bog ecosystem, Sphagnum, is a reservoir for potentially opportunistic human pathogens $[14,65]$. In this study, we also identified a list of potential human pathogens, i.e. Clamydia and Mycobacterium spec. div. Therefore, we searched for potential virulence factor homologs $(\geq 50 \%$ identity and $<1 \mathrm{e}-10 \mathrm{E}$-value) that are prevalent among the MAGs (Table S8). Calculation of the average distance of the MAGs and clinical isolate genomes indicated cluster formation that was mainly attributable to bacterial class level (Figure S3). This result was strengthened by PERMANOVA analysis which indicated that the origin of isolates (clinical and environment) only explained a small variation virulence gene composition $\left(R^{2}=2.4 \%\right)$ while taxonomical identity explained $29.6 \%$ of the variation. There was no clear differentiation in the virulence gene composition between the genomes of closely related clinical and environmental isolates within the clusters. Nevertheless, we identified a number of genes that were exclusively detected in the bog
MAGs in comparison to the closely related clinical isolate genomes. For instance, when MAG 172 was compared with a clinical Mycobacterium, MAG12 with clinical Chlamydia isolates and MAG_111 with clinical Sphingomonas isolates, bog-specific differences were found (Figure S4; Table S9). When analysed in detail, a gene that encodes catalase peroxidase (katA) was detected in MAGs 110 and 172 but was not present in the clinical isolates. Specific genes that are involved in iron uptake, i.e. $c c m, y b t Q$ and $m b t J$, were also only present in MAGs generated from the bog ecosystem when compared to their closely related clinical taxa. Genes encoding the phytotoxin phaseolotoxin were exclusively detected in MAGs 111 and 139 that belong to Sphingomonadaceae and Betaproteobacteria, respectively.

\section{Discussion}

In the present study, we showed that vascular plants and bryophytes enrich certain bacterial taxa with distinct functional properties reflecting plant-microbe coevolution. The differences in community composition were statistically significant despite the fact that all analysed plant species co-occur in close proximity and are connected by a bacterial meta-community [11]. Plantmicrobe coevolution was already reported for distinct plants, interactions and processes [17, 24]; here, we show complementary implications at the ecosystem level by employing a shotgun metagenomic sequencing approach using a novel bioinformatic pipeline and detailed genome-centric analysis. Compared with previous studies, we found concordance in terms of the prevalence of Proteobacteria, but also observed differences in the relative abundance of less abundant taxa [11]. This is commonly observed when studies based on the amplification of marker genes are compared with such based on shotgun metagenomics [66-68]. In this context, it is noteworthy to mention that using shotgun metagenomics we detected a higher number of bacterial taxa (5699 vs. 4898 bacterial OTUs/species). Bogs are important native models to study general rules of plant-microbe coevolution and specificity, because these ecosystems have been stable for centuries and are shaped by extreme but similar abiotic factors around the world [69-71]. In addition to confirming previous findings with complementary approaches, we further illustrated that the bog microbiome is collectively involved in beneficial functions, which are referred to as microbiome services, i.e. nutrient supply, plant growth promotion and vitamin biosynthesis to support bog ecosystem functioning (Fig. 6).

Bryophytes were found to be associated with a significantly higher bacterial richness and diversity in comparison to vascular plants. Nevertheless, the bacterial alpha diversity was found to be in a similar range for 


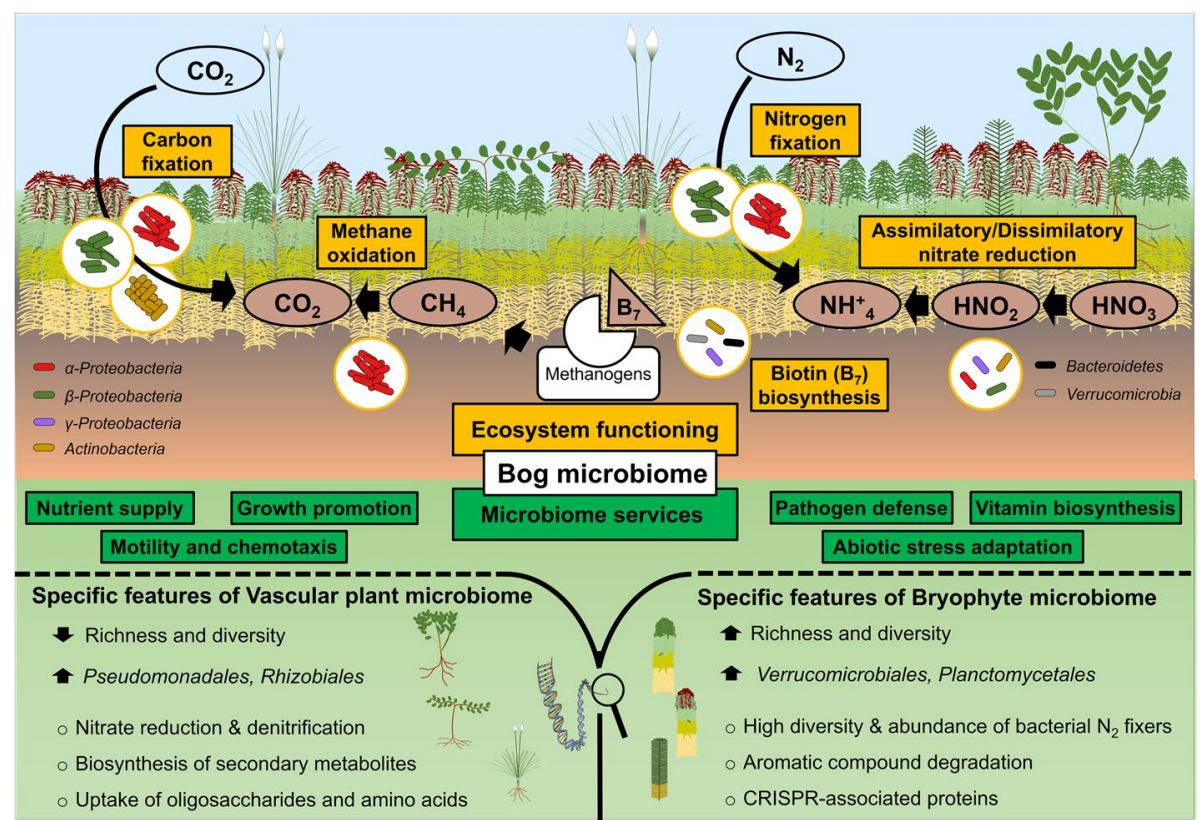

Fig. 6 Schematic illustration of bacterial groups associated with vascular plants and bryophytes contributing to bog ecosystem functioning. Different bacterial groups involved in bog ecosystem functioning are indicated by different colours (red: Alphaproteobacteria, green: Betaproteobacteria, purple: Gammaproteobacteria, gold: Actinobacteria, blue: Acidobacteria, black: Bacteroidetes and grey: Verrucomicrobia). Overall microbiome services and plant-specific (for bryophytes and vascular plants) traits were included in the lower part of the figure

both plant systems. We argue that the spatial proximity of plants facilitates the transfer of microorganisms, leading to an increase in overall diversity while maintaining plant group specificity. Bryophytes, including Sphagnum mosses, provide an exceptional habitat for plant-associated bacteria and their richness is tightly connected with the bog ecosystem functioning [27]. A recent study showed that a decline in the microbial diversity of Sphagnum mosses was correlated with a decrease in $\mathrm{N}_{2}$ fixation activity [72], which highlights the importance of bacterial richness for the overall bog ecosystem functioning. The community composition was more similar among different bryophytes, and more different between the vascular plant species. The latter are known to recruit a specific fraction of bacterial taxa from their surrounding environment due to secretory activities in their root system [16], which is also suggested as an entry point for bacteria to colonize above-ground plant compartments [73]. In vascular plants, bacterial diversity is commonly reduced from soil to rhizosphere to endosphere [16]. In contrast, bryophytes, which lack functional root structures, do not rely on their belowground compartments to recruit bacteria. Processes of water and mass transfer run over the entire surface of the plants. They can maintain a high bacterial diversity within the whole lifecycle, independent of their respective environment [23]. A foregoing study indicated that the liverwort Marchantia paleacea harboured a higher bacterial diversity than its soil substrate [74]. Vascular plants are more influenced by host-environmental interactions especially in the bog ecosystem with its extreme conditions, i.e. low $\mathrm{pH}$, nutrient and high water saturation $[4,23]$.

When bacterial community composition was explored in the present study, a subset of differing bacterial features was detected between vascular plants and bryophytes indicating that the analysed plant hosts harboured functionally adapted bacterial communities. In the bog ecosystem, vascular plants and bryophytes grow in close proximity and are mostly embedded in the predominant Sphagnum plants. Therefore, it was to be expected that a majority of the prevalent bacteria and their functions, i.e. $A B C$ transporters, quorum sensing, nitrogen metabolism and biosynthesis of siderophores, are widely shared by hosts as already shown before by marker gene analyses [8, 12, 28]. Nevertheless, plant-specific differences in the bacterial community, especially at the bacterial order level and below, as well as their function were observed. Previous studies have provided concordant results for specific functional groups in these environments $[23,75,76]$; however, they did not assess the entire taxonomic and functional diversity in typical bog ecosystems. Coevolution between microbes and hosts has apparently led to nuanced functional specificity in different plant groups. We detected a higher abundance of 
bacterial genes involved in aromatic compound degradation in bryophytes that might be explained by the typical accumulation of the aromatic compound in Sphagnum bogs that can be used as a carbon source by bacteria [77, 78]. In nutrient-poor environments, bryophytes such as Sphagnum mosses can absorb and accumulate mineral nutrients all over their surface highly effective even in extreme nutrient-poor environments, which gives them a competitive advantage over the vascular plant [79]. In contrast, root systems of typical vascular plants in bog ecosystems, e.g. Eriophorum vaginatum, Calluna vulgaris, Vaccinium myrtillus and Vaccinium oxycoccus that were included in the present study, can penetrate into deeper portions of the bog with their root systems $[6,28]$. $\mathrm{ABC}$ transporter genes that are involved in the uptake of oligosaccharides and amino acids were enriched in the vascular plants. Enrichment of bacteria with this function might be more important for microbes of vascular plants growing in bogs to increase nutrient uptake from the environment and support their growth under nutrient-limited conditions.

Bacterial communities of bryophytes and vascular plants were shown to harbour different nitrogen cycling gene profiles. In nitrogen-poor environments, bacteria play a crucial role in nitrogen acquisition for the growth and development of plants (reviewed in [80, 81]). Nitrogen-fixing bacteria with nifH genes were shown to be more prevalent in bryophytes in comparison to vascular plants when an extended reference database was used. It should be noted that when solely using the eggNOG database, the abundance of nifH genes was found to be higher in vascular plants. However, the read number that was identified by using the eggNOG database was substantially lower (898 reads) when compared to NCycDB database hits (7608 reads). NCycDB was constructed by integrating nitrogen cycling genes from various databases (COG, KEGG, SEED and eggNOG) and thus provides a better reference set for assignments. This result also highlighted that bryophytes, especially Sphagnum, contained a high diversity of bacterial genes involved in nitrogen fixation. It is in agreement with previous findings describing the potential of nitrogen-fixing bacteria in bogs and possible occurrence of novel nifH variants [27]. Hence, this observation corroborates the importance of nitrogen-fixing bacteria which were mainly assigned to Alphaproteobacteria, for Sphagnum mosses [4, 8, 12]. In contrast to the observed abundance of nifH genes, a higher number of genes encoding nitrate reductases for denitrification processes were observed in metagenomes of vascular plants. The results are in accordance with previous findings that different plant species harbour specific microbial communities with specific functions even when grown on the same environment $[82,83]$.
By including a detailed genome-centric analysis of microbial communities, we were able to identify the metabolic potential of individual MAGs and highlight the specific roles of each functional guild. Alpha-, Beta- and Actinobacteria likely play an important role in carbon fixation in this ecosystem. Previous studies have shown that autotrophic bacteria within the bacterial phyla Proteobacteria and Actinobacteria significantly contribute to carbon fixation in various environments $[84,85]$. Furthermore, they account for up to $4 \%$ of the total $\mathrm{CO}_{2}$ fixed by terrestrial ecosystems each year [86]. To our knowledge, so far, only few studies reported this bacterial feature from the bog ecosystem $[87,88]$. Here, we showed that novel lineages of Betaproteobacteria and Actinobacteria that are found in the bog also harbour similar features involved in carbon fixation. MAGs that were assigned to these taxa are likely capable to fix carbon via $\mathrm{RuBisCo}$. They were also shown to possess isocitrate lyase, a key enzyme involved in the glyoxylate shunt [88]. In analogy to our study, this strategy to fix carbon, which likely occurs when carbohydrates from the plant that are needed for biomass production by the bacteria are scarce, has been previously described in a novel bacterial lineage associated with moss species and named candidate phylum WPS-2 [87]. Alpha-, Beta-, Gammaproteobacteria and Actinobacteria likely play important roles in controlling and balancing the amount of available nitrogen in the bog ecosystem due to the presence of genes that are involved in assimilatory/dissimilatory nitrate reduction. Sphagnum can efficiently uptake ammonium and use it as the main nitrogen source [89, 90]; thus, Alpha-, Beta-, Gammaproteobacteria and Actinobacteria likely provide additional available ammonium through assimilatory/dissimilatory nitrate reduction. In addition, our data suggests that Acidobacteria, Bacteroidetes and Verrucomicrobia play an important role in sulfur metabolism by catalysing the oxidation of thiosulfate to sulfate employing the Sox system [91], which was indicated by the presence of $\operatorname{sox} B, \operatorname{sox} X$ and $\operatorname{sox} Y$ genes. Overall, we could detect specific functional guilds that fulfil distinct roles related to key nutrient cycles in the bog ecosystem.

Other detected functions such as vitamin supply and resistance against biotic and abiotic stress factors indicate interactions with the host plants. Actinobacteria, Gammaproteobacteria, Bacteroidetes and Verrucomicrobia were shown to take part in biotin metabolism that might be also needed for stimulating the growth of some methanogens [92, 93]. Our findings suggest that Actinobacteria are involved in vitamin K2 biosynthesis due to the presence of genes involved in menaquinone biosynthesis. Vitamin K2 is involved in photosynthesis as a predominant electron carrier under low oxygen concentration [94, 95], a typical condition at the surface of peatlands 
[4]. Terpenoid synthesis genes that were identified within MAGs indicated clear segregation into mevalonate and MEP/DOXP (non-mevalonate) pathways. Moreover, Proteobacteria were shown to be well equipped with defence mechanisms against oxidative stress and heat shock due to a frequent occurrence of genes encoding molecular chaperones Hsp33 ( $h s l O)$ and Hsp20 (ibpAB) [96, 97].

Interestingly, we also detected diverse putative virulence genes with high homology to sequences in the MAGs. The identified virulence genes allow human pathogenic bacteria to establish infections, survive in the hostile host environment and cause diseases [61]. However, in nature, the virulence genes such as flagella, the O-antigen of lipopolysaccharides and molecular chaperones facilitate bacterial colonization of their host plants $[98,99]$. Previously, potential facultative pathogens were isolated from bog environments $[14,65]$. This study reinforces previous observations that there is no clear separation between clinical and environmental isolates [100]. A similar result was previously reported in a study by Lira and colleagues [101]. When comparing clinical and environmental genomes of Stenotrophomonas maltophilia strains, they found that genomic composition is not sufficient to differentiate clinical and environmental isolates. Therefore, the presence of virulence genes that encode adherence-related proteins, stress-related proteins and iron uptake proteins may be used by the MAGs to overcome the plant defence system and efficiently colonize the host plants, especially vascular plants, in their natural environment [102]. However, these genes can become pathogenicity factors when transferred to other environments. In the present study, we could even show that some environmental isolates can harbour more virulence factors than their clinical counterparts, which further confirms that many human pathogens likely originated in the environment.

\section{Conclusion}

Differences in the abundance of specific bacterial taxa with distinct functions between vascular plants and bryophytes indicate coevolution with their host plants. By employing genome-centric analyses, we could identify a highly complex metabolic potential within the bog microbiome and expand our understanding of the role of microorganisms in bog vegetation. The extraordinary high functional microbial diversity discovered in bog ecosystems allows understanding of stability, functioning and ecosystem health in bogs. However, this includes a high diversity of antimicrobial resistance as well as virulence genes, which indicates not only a reservoir for multi-resistant pathogens but also a source for studying suppression of them under natural conditions and emergence under anthropogenic influence.

\section{Supplementary Information}

The online version contains supplementary material available at https://doi. org/10.1186/s40168-021-01117-7.

Additional file 1: Figure S1. Rarefaction curves showing the number of metagenomic reads that were classified as bacterial sequences according to the Kraken2 classifier. Figure S2. Bacterial community clustering at phylum (a), class (b), order (c) and genus (d) level was visualized in two-dimensional Bray Curtis PCoA plots. Figure S3. Analysis of virulence gene composition of clinical and environmental bog isolates. Hierarchical clustering of clinical and environmental strains is based in the presence/ absence of virulence genes in the genome. Figure S4. Venn diagrams showing the numbers of shared and unique virulence genes detected in clinical and environmental bog isolate genomes. The graph was generated using InteractiVenn [61]. Table S1. Description of vegetation field plots regarding habitat characteristics and plant coverage per plot. Table S2. List of the 12 plant species that were included to represent the vegetation of a Sphagnum-dominated bog ecosystem. Table S3. Detailed taxonomical classification, source of origin and NCBI accessions of clinical and environmental isolate genomes. Table S4. List of the KEGG orthologs that were significantly enriched between bryophytes and vascular plants. Table S5. List of the pathways and genes involved in nitrogen cycling that were significantly enriched in either bryophytes or vascular plants. Table S6. Detailed taxonomic classification, completeness, contamination values, and genome sizes of bacterial MAGs. Table S7. Abundance estimation of metagenome assembled genomes in each plant sample. Table S8. Prevalence of putative virulence factors as predicted for metagenomeassembled genomes (MAGs) using the virulence factor database (VFDB). Table S9. Putative virulence factors that were uniquely present in the MAGs generated from the bog ecosystem when compared to their closely related clinical isolates.

\section{Acknowledgements}

We thank Barbara Fetz, Anastasia Bragina and Melanie Obermeier (all Graz) for the technical support during the initial processing of the samples.

\section{Authors' contributions}

C.B. and G.B. designed and performed the sampling, and G.B. and T.C. designed the study. W.A.W. performed the research and analysed the bioinformatic data. W.A.W., T.C. and G.B. wrote the manuscript. All authors discussed results and commented on the manuscript at all stages. The author(s) read and approved the final manuscript.

Funding

This study was financially supported by a grant to G.B. (grant no. E-1653100183) from the Austrian Science Foundation FWF. The funders had no role in the study design, data collection and analysis, decision to publish, or preparation of the manuscript.

\section{Availability of data and materials}

This shotgun metagenome project has been deposited in the European Nucleotide Archive (ENA) database under the study number PRJEB39100 and accession numbers ERR4298333 and ERR4298344.

\section{Declarations}

Ethics approval and consent to participate Not applicable.

\section{Consent for publication}

Not applicable.

\section{Competing interests}

The authors declare that they have no competing interests.

\section{Author details}

${ }^{1}$ Institute of Environmental Biotechnology, Graz University of Technology, Graz, Austria. ${ }^{2}$ Institute of Plant Sciences, University of Graz, Graz, Austria. 
${ }^{3}$ Leibniz Institute for Agricultural Engineering and Bioeconomy (ATB), Potsdam, Germany. ${ }^{4}$ Institute for Biochemistry and Biology, University of Postdam, Postdam, Germany.

Received: 25 February 2021 Accepted: 21 June 2021 Published online: 11 August 2021

\section{References}

1. Raghoebarsing AA, Smolders AJ, Schmid MC, Rijpstra WIC, WoltersArts M, Derksen J, et al. Methanotrophic symbionts provide carbon for photosynthesis in peat bogs. Nature. 2005:436:1153-6.

2. Hopple A, Wilson R, Kolton M, Zalman CA, Chanton JP, Kostka J, et al. Massive peatland carbon banks vulnerable to rising temperatures. Nat Commun. 2020;11:1-7.

3. Dise NB. Peatland response to global change. Science. 2009;326:810-1.

4. Kostka JE, Weston DJ, Glass JB, Lilleskov EA, Shaw AJ, Turetsky MR. The Sphagnum microbiome: new insights from an ancient plant lineage. New Phytol. 2016;211:57-64.

5. Groeneveld EV, Masse A, Rochefort L. Polytrichum strictum as a nurseplant in peatland restoration. Restor Ecol. 2007;15:709-19.

6. Malmer N, Svensson BM, Wallén B. Interactions between Sphagnum mosses and field layer vascular plants in the development of peatforming systems. Folia Geobot Phytotaxon. 1994;29:483-96.

7. Pouliot R, Rochefort L, Karofeld E, Mercier C. Initiation of Sphagnum moss hummocks in bogs and the presence of vascular plants: is there a link? Acta Oecologica. 2011:37:346-54

8. Bragina A, Oberauner-Wappis L, Zachow C, Halwachs B, Thallinger GG, Müller $\mathrm{H}$, et al. The Sphagnum microbiome supports bog ecosystem functioning under extreme conditions. Mol Ecol. 2014;23:4498-510.

9. Larmola T, Leppänen SM, Tuittila E-S, Aarva M, Merilä P, Fritze H, et al. Methanotrophy induces nitrogen fixation during peatland development. Proc Natl Acad Sci. 2014;111:734-9.

10. Hausmann B, Knorr K-H, Schreck K, Tringe SG, Del Rio TG, Loy A, et al. Consortia of low-abundance bacteria drive sulfate reduction-dependent degradation of fermentation products in peat soil microcosms. ISME J. 2016;10:2365-75.

11. Bragina A, Berg C, Berg G. The core microbiome bonds the Alpine bog vegetation to a transkingdom metacommunity. Mol Ecol. 2015;24:4795-807

12. Opelt K, Chobot V, Hadacek F, Schönmann S, Eberl L, Berg G. Investigations of the structure and function of bacterial communities associated with Sphagnum mosses. Environ Microbiol. 2007;9:2795-809.

13. Woodcroft BJ, Singleton CM, Boyd JA, Evans PN, Emerson JB, Zayed AA, et al. Genome-centric view of carbon processing in thawing permafrost. Nature. 2018;560:49-54.

14. Obermeier MM, Wicaksono WA, Taffner J, Bergna A, Poehlein A, Cernava T, et al. Plant resistome profiling in evolutionary old bog vegetation provides new clues to understand emergence of multi-resistance. ISME J. 2021;15:921-37.

15. Berg G, Rybakova D, Grube M, Köberl M. The plant microbiome explored: implications for experimental botany. J Exp Bot. 2016;67:995-1002.

16. Bulgarelli D, Schlaeppi K, Spaepen S, Van Themaat EVL, Schulze-Lefert P. Structure and functions of the bacterial microbiota of plants. Annu Rev Plant Biol. 2013;64:807-38.

17. Cordovez V, Dini-Andreote F, Carrión VJ, Raaijmakers JM. Ecology and evolution of plant microbiomes. Annu Rev Microbiol. 2019;73:69-88.

18. Bragina A, Maier S, Berg C, Müller H, Chobot V, Hadacek F, et al. Similar diversity of Alphaproteobacteria and nitrogenase gene amplicons on two related Sphagnum mosses. Front Microbiol. 2012:2:275.

19. Opelt K, Berg C, Schönmann S, Eberl L, Berg G. High specificity but contrasting biodiversity of Sphagnum-associated bacterial and plant communities in bog ecosystems independent of the geographical region. ISME J. 2007;1:502-16.

20. Shcherbakov A, Bragina A, Kuzmina EY, Berg C, Muntyan A, Makarova N, et al. Endophytic bacteria of Sphagnum mosses as promising objects of agricultural microbiology. Microbiology. 2013;82:306-15.
21. Pankratov TA, Ivanova AO, Dedysh SN, Liesack W. Bacterial populations and environmental factors controlling cellulose degradation in an acidic Sphagnum peat. Environ Microbiol. 2011;13:1800-14.

22. Dedysh SN, Ivanova AA. Planctomycetes in boreal and subarctic wetlands: diversity patterns and potential ecological functions. FEMS Microbiol Ecol. 2019;95:fiy227.

23. Bragina A, Berg C, Cardinale M, Shcherbakov A, Chebotar V, Berg G. Sphagnum mosses harbour highly specific bacterial diversity during their whole lifecycle. ISME J. 2012;6:802-13.

24. Baltrus DA. Adaptation, specialization, and coevolution within phytobiomes. Curr Opin Plant Biol. 2017;38:109-16.

25. Ponce de León I, Montesano M. Activation of defense mechanisms against pathogens in mosses and flowering plants. Int J Mol Sci. 2013:14:3178-200

26. Fricker AM, Podlesny D, Fricke WF. What is new and relevant for sequencing-based microbiome research? A mini-review. J Adv Res. 2019;19:105-12.

27. Bragina A, Berg C, Müller H, Moser D, Berg G. Insights into functional bacterial diversity and its effects on Alpine bog ecosystem functioning. Sci Rep. 2013;3:1-8.

28. Taffner J, Erlacher A, Bragina A, Berg C, Moissl-Eichinger C, Berg G. What is the role of Archaea in plants? New insights from the vegetation of alpine bogs. MSphere. 2018;3(3):e00122-18.

29. Lu J, Breitwieser FP, Thielen P, Salzberg SL. Bracken: estimating species abundance in metagenomics data. PeerJ Comput Sci. 2017;3:e104

30. Wood DE, Lu J, Langmead B. Improved metagenomic analysis with Kraken 2. Genome Biol. 2019:20:257.

31. Paulson JN, Stine OC, Bravo HC, Pop M. Differential abundance analysis for microbial marker-gene surveys. Nat Methods. 2013;10:1200-2.

32. Allaire J. RStudio: integrated development environment for R. Boston MA. 2012:770:394.

33. Chong J, Liu P, Zhou G, Xia J. Using MicrobiomeAnalyst for comprehensive statistical, functional, and meta-analysis of microbiome data. Nat Protoc. 2020;15:799-821.

34. Core Team R. R: a language and environment for statistical computing. Vienna: R Foundation for Statistical Computing; 2013.

35. Dhariwal A, Chong J, Habib S, King IL, Agellon LB, Xia J. MicrobiomeAnalyst: a web-based tool for comprehensive statistical, visual and meta-analysis of microbiome data. Nucleic Acids Res. 2017:45:W180-8.

36. McMurdie PJ, Holmes S. phyloseq: an R package for reproducible interactive analysis and graphics of microbiome census data. PLoS One. 2013;8(4):e61217.

37. Oksanen J, Kindt R, Legendre P, O'Hara B, Stevens MHH, Oksanen MJ, et al. The vegan package. Community Ecol Package. 2007;10:631-7.

38. Segata N, Izard J, Waldron L, Gevers D, Miropolsky L, Garrett WS, et al. Metagenomic biomarker discovery and explanation. Genome Biol. 2011;12:1-18.

39. Andrews S. FastQC: a quality control tool for high throughput sequence data. 2010

40. Li D, Liu C-M, Luo R, Sadakane K, Lam T-W. MEGAHIT: an ultra-fast single-node solution for large and complex metagenomics assembly via succinct de Bruijn graph. Bioinformatics. 2015;31:1674-6.

41. Hyatt D, Chen G-L, LoCascio PF, Land ML, Larimer FW, Hauser LJ. Prodigal: prokaryotic gene recognition and translation initiation site identification. BMC Bioinformatics. 2010;11:119.

42. Li W, Godzik A. Cd-hit: a fast program for clustering and comparing large sets of protein or nucleotide sequences. Bioinformatics. 2006;22:1658-9.

43. Buchfink B, Xie C, Huson DH. Fast and sensitive protein alignment using DIAMOND. Nat Methods. 2015;12:59.

44. Huerta-Cepas J, Forslund K, Coelho LP, Szklarczyk D, Jensen LJ, Von Mering $C$, et al. Fast genome-wide functional annotation through orthology assignment by eggNOG-mapper. Mol Biol Evol. 2017;34:2115-22.

45. Huerta-Cepas J, Szklarczyk D, Heller D, Hernández-Plaza A, Forslund SK, Cook H, et al. eggNOG 5.0: a hierarchical, functionally and phylogenetically annotated orthology resource based on 5090 organisms and 2502 viruses. Nucleic Acids Res. 2019;47:D309-14. 
46. Li H, Handsaker B, Wysoker A, Fennell T, Ruan J, Homer N, et al. The sequence alignment/map format and SAMtools. Bioinformatics. 2009;25:2078-9.

47. Li H, Durbin R. Fast and accurate long-read alignment with BurrowsWheeler transform. Bioinformatics. 2010;26:589-95.

48. Jonsson V, Österlund T, Nerman O, Kristiansson E. Statistical evaluation of methods for identification of differentially abundant genes in comparative metagenomics. BMC Genomics. 2016;17:78.

49. Robinson MD, McCarthy DJ, Smyth GK. edgeR: a bioconductor package for differential expression analysis of digital gene expression data. Bioinformatics. 2010;26:139-40.

50. Kanehisa M, Sato Y. KEGG Mapper for inferring cellular functions from protein sequences. Protein Sci. 2020;29:28-35.

51. Tu Q, Lin L, Cheng L, Deng Y, He Z. NCycDB: a curated integrative database for fast and accurate metagenomic profiling of nitrogen cycling genes. Bioinformatics. 2019;35:1040-8.

52. Zhang J, Buhe C, Yu D, Zhong H, Wei Y. Ammonia stress reduces antibiotic efflux but enriches horizontal gene transfer of antibiotic resistance genes in anaerobic digestion. Bioresour Technol. 2020;295:122191.

53. Alneberg J, Bjarnason BS, De Bruijn I, Schirmer M, Quick J, ljaz UZ, et al. Binning metagenomic contigs by coverage and composition. Nat Methods. 2014;11:1144-6.

54. Kang DD, Li F, Kirton E, Thomas A, Egan R, An H, et al. MetaBAT 2: an adaptive binning algorithm for robust and efficient genome reconstruction from metagenome assemblies. PeerJ. 2019;7:e7359.

55. Wu Y-W, Simmons BA, Singer SW. MaxBin 2.0: an automated binning algorithm to recover genomes from multiple metagenomic datasets. Bioinformatics. 2016;32:605-7.

56. Wicaksono WA, Cernava T, Berg C, Berg G. Reconstruction of bacterial metagenome-assembled genome sequences from Alpine bog vegetation. Microbiol Resour Announc. 2020;9(35):e00821-20.

57. Sieber CM, Probst AJ, Sharrar A, Thomas BC, Hess M, Tringe SG, et al. Recovery of genomes from metagenomes via a dereplication, aggregation and scoring strategy. Nat Microbiol. 2018;3:836-43.

58. Parks DH, Imelfort M, Skennerton CT, Hugenholtz P, Tyson GW. CheckM: assessing the quality of microbial genomes recovered from isolates, single cells, and metagenomes. Genome Res. 2015;25:1043-55.

59. Bowers RM, Kyrpides NC, Stepanauskas R, Harmon-Smith M, Doud D, Reddy $T$, et al. Minimum information about a single amplified genome (MISAG) and a metagenome-assembled genome (MIMAG) of bacteria and archaea. Nat Biotechnol. 2017;35:725-31.

60. von Meijenfeldt FB, Arkhipova K, Cambuy DD, Coutinho FH, Dutilh BE. Robust taxonomic classification of uncharted microbial sequences and bins with CAT and BAT. Genome Biol. 2019;20:217.

61. Chen L, Zheng D, Liu B, Yang J, Jin Q. VFDB 2016: hierarchical and refined dataset for big data analysis - 10 years on. Nucleic Acids Res. 2016:44:D694-7.

62. Zhang H, Zhang Q, Song J, Zhang Z, Chen S, Long Z, et al. Tracking resistomes, virulence genes, and bacterial pathogens in long-term manure-amended greenhouse soils. J Hazard Mater. 2020;396:122618.

63. Asnicar F, Thomas AM, Beghini F, Mengoni C, Manara S, Manghi P, et al Precise phylogenetic analysis of microbial isolates and genomes from metagenomes using PhyloPhIAn 3.0. Nat Commun. 2020;11:1-10.

64. Heberle H, Meirelles GV, da Silva FR, Telles GP, Minghim R. InteractiVenn: a web-based tool for the analysis of sets through Venn diagrams. BMC Bioinformatics. 2015;16:1-7.

65. Opelt K, Berg C, Berg G. The bryophyte genus Sphagnum is a reservoir for powerful and extraordinary antagonists and potentially facultative human pathogens. FEMS Microbiol Ecol. 2007;61:38-53.

66. Durazzi F, Sala C, Castellani G, Manfreda G, Remondini D, De Cesare A. Comparison between $16 \mathrm{~S}$ rRNA and shotgun sequencing data for the taxonomic characterization of the gut microbiota. Sci Rep. 2021;11:1-10

67. Taffner J, Cernava T, Erlacher A, Berg G. Novel insights into plant-associated archaea and their functioning in arugula (Eruca sativa Mill.). J Adv Res. 2019:19:39-48.

68. Regalado J, Lundberg DS, Deusch O, Kersten S, Karasov T, Poersch K, et al. Combining whole-genome shotgun sequencing and rRNA gene amplicon analyses to improve detection of microbe-microbe interaction networks in plant leaves. ISME J. 2020;14:2116-30.
69. Pedrotti $E$, Rydin $H$, Ingmar $T$, Hytteborn $H$, Turunen $P$, Granath $G$. Fine-scale dynamics and community stability in boreal peatlands: revisiting a fen and a bog in Sweden after 50 years. Ecosphere. 2014;5:1-24.

70. Chaudhary N, Miller PA, Smith B. Biotic and abiotic drivers of peatland growth and microtopography: a model demonstration. Ecosystems. 2018;21:1196-214.

71. Robroek BJ, Jassey VE, Payne RJ, Martí M, Bragazza L, Bleeker A, et al. Taxonomic and functional turnover are decoupled in European peat bogs. Nat Commun. 2017;8:1-9.

72. Carrell AA, Kolton M, Glass JB, Pelletier DA, Warren MJ, Kostka JE, et al. Experimental warming alters the community composition, diversity, and $\mathrm{N}_{2}$ fixation activity of peat moss (Sphagnum fallax) microbiomes. Glob Change Biol. 2019;25:2993-3004.

73. Compant S, Clément C, Sessitsch A. Plant growth-promoting bacteria in the rhizo-and endosphere of plants: their role, colonization, mechanisms involved and prospects for utilization. Soil Biol Biochem. 2010;42:669-78.

74. Alcaraz LD, Peimbert M, Barajas HR, Dorantes-Acosta AE, Bowman $J$, Arteaga-Vázquez MA. Marchantia liverworts as a proxy to plants' basal microbiomes. Sci Rep. 2018;8:1-12.

75. Lebeis SL, Paredes SH, Lundberg DS, Breakfield N, Gehring J, McDonald M, et al. Salicylic acid modulates colonization of the root microbiome by specific bacterial taxa. Science. 2015;349:860-4.

76. Turner TR, Ramakrishnan K, Walshaw J, Heavens D, Alston M, Swarbreck D, et al. Comparative metatranscriptomics reveals kingdom level changes in the rhizosphere microbiome of plants. ISME J. 2013;7:2248-58.

77. Belova S, Pankratov T, Dedysh S. Bacteria of the genus Burkholderia as a typical component of the microbial community of Sphagnum peat bogs. Microbiology. 2006;75:90-6.

78. Kracht $\mathrm{O}$, Gleixner $\mathrm{G}$. Isotope analysis of pyrolysis products from Sphagnum peat and dissolved organic matter from bog water. Org Geochem. 2000;31:645-54.

79. Malmer N. Mineral nutrients in vegetation and surface layers of Sphagnum-dominated peat-forming systems. Adv Bryol. 1993;5:223-48.

80. Kraiser T, Gras DE, Gutiérrez AG, González B, Gutiérrez RA. A holistic view of nitrogen acquisition in plants. J Exp Bot. 2011;62:1455-66.

81. Moreau D, Bardgett RD, Finlay RD, Jones DL, Philippot L. A plant perspective on nitrogen cycling in the rhizosphere. Funct Ecol. 2019;33:540-52.

82. Berendsen RL, Pieterse CM, Bakker PA. The rhizosphere microbiome and plant health. Trends Plant Sci. 2012;17:478-86.

83. Berg G, Smalla K. Plant species and soil type cooperatively shape the structure and function of microbial communities in the rhizosphere. FEMS Microbiol Ecol. 2009;68:1-13.

84. Hügler M, Sievert SM. Beyond the Calvin cycle: autotrophic carbon fixation in the ocean. Annu Rev Mar Sci. 2011:3:261-89.

85. Lynn TM, Ge T, Yuan H, Wei X, Wu X, Xiao K, et al. Soil carbon-fixation rates and associated bacterial diversity and abundance in three natural ecosystems. Microb Ecol. 2017;73:645-57.

86. Yuan H, Ge T, Chen C, O'Donnell AG, Wu J. Significant role for microbial autotrophy in the sequestration of soil carbon. Appl Environ Microbiol. 2012;78:2328-36.

87. Holland-Moritz H, Stuart J, Lewis LR, Miller S, Mack MC, McDaniel SF et al. Novel bacterial lineages associated with boreal moss species. Environ Microbiol. 2018;20:2625-38.

88. Singleton CM, McCalley CK, Woodcroft BJ, Boyd JA, Evans PN, Hodgkins SB, et al. Methanotrophy across a natural permafrost thaw environment. ISME J. 2018;12:2544-58.

89. Fritz C, Lamers LP, Riaz M, van den Berg LJ, Elzenga TJ. Sphagnum mosses-masters of efficient $\mathrm{N}$-uptake while avoiding intoxication. PLOS One. 2014:9:e79991.

90. Liu X, Koba K, Makabe A, Li X, Yoh M, Liu C. Ammonium first: natural mosses prefer atmospheric ammonium but vary utilization of dissolved organic nitrogen depending on habitat and nitrogen deposition. New Phytol. 2013;199:407-19.

91. Frigaard N-U, Dahl C. Sulfur metabolism in phototrophic sulfur bacteria. Adv Microb Physiol. 2008;54:103-200. 
92. Widdel F. Growth of methanogenic bacteria in pure culture with 2-propanol and other alcohols as hydrogen donors. Appl Environ Microbiol. 1986;51:1056-62.

93. Zhu X, Campanaro S, Treu L, Seshadri R, Ivanova N, Kougias PG, et al. Metabolic dependencies govern microbial syntrophies during methanogenesis in an anaerobic digestion ecosystem. Microbiome. 2020;8:1-14.

94. Cenci U, Qiu H, Pillonel T, Cardol P, Remacle C, Colleoni C, et al. Hostpathogen biotic interactions shaped vitamin K metabolism in Archaeplastida. Sci Rep. 2018;8:1-14.

95. Hale MB, Blankenship RE, Fuller RC. Menaquinone is the sole quinone in the facultatively aerobic green photosynthetic bacterium Chloroflexus aurantiacus. Biochim Biophys Acta BBA-Bioenerg. 1983;723:376-82.

96. Krewing M, Stepanek JJ, Cremers C, Lackmann J-W, Schubert B, Müller A, et al. The molecular chaperone Hsp33 is activated by atmosphericpressure plasma protecting proteins from aggregation. J R Soc Interface. 2019;16:20180966.

97. LeThanh $\mathrm{H}$, Neubauer $\mathrm{P}$, Hoffmann F. The small heat-shock proteins $\mathrm{IbpA}$ and IbpB reduce the stress load of recombinant Escherichia coli and delay degradation of inclusion bodies. Microb Cell Factories. 2005;4:6.
98. Berg G, Eberl L, Hartmann A. The rhizosphere as a reservoir for opportunistic human pathogenic bacteria. Environ Microbiol. 2005;7:1673-85.

99. Pinski A, Betekhtin A, Hupert-Kocurek K, Mur LA, Hasterok R. Defining the genetic basis of plant-endophytic bacteria interactions. Int J Mol Sci. 2019:20:1947.

100. Casadevall A. The pathogenic potential of a microbe. Msphere. 2017:2(1):e00015-17.

101. Lira F, Berg G, Martínez JL. Double-face meets the bacterial world: the opportunistic pathogen Stenotrophomonas maltophilia. Front Microbiol. 2017:8:2190.

102. Reinhold-Hurek B, Bünger W, Burbano CS, Sabale M, Hurek T. Roots shaping their microbiome: global hotspots for microbial activity. Annu Rev Phytopathol. 2015;53:403-24.

\section{Publisher's Note}

Springer Nature remains neutral with regard to jurisdictional claims in published maps and institutional affiliations.
Ready to submit your research? Choose BMC and benefit from:

- fast, convenient online submission

- thorough peer review by experienced researchers in your field

- rapid publication on acceptance

- support for research data, including large and complex data types

- gold Open Access which fosters wider collaboration and increased citations

- maximum visibility for your research: over $100 \mathrm{M}$ website views per year

At $\mathrm{BMC}$, research is always in progress.

Learn more biomedcentral.com/submissions 